\title{
PROGRAM PAUD HOLISTIK DI SEKOLAH BINARRAHMAN KOTA SEMARANG
}

\author{
Vilda Ana Veria Setyawati ${ }^{1}$, Eti Rimawati ${ }^{2}$ \\ ${ }^{1,2}$ Kesehatan Masyarakat, Universitas Dian Nuswantoro \\ E-mail:' ${ }^{1}$ vilda.setyawati@dsn.dinus.ac.id, ${ }^{2}$ eti.rimawati@dsn.dinus.ac.id
}

\begin{abstract}
Abstrak
Pemerintah telah menetapkan bahwa PAUD yang didirikan harus memenuhi PAUD Holistik, sesuai dengan Peraturan Presiden (PERPRES) No 60 Tahun 2013 tentang PAUD Holistik. PAUD Holistik Integratif adalah penanganan anak usia dini secara utuh (menyeluruh) yang mencakup layanan gizi dan kesehatan, pendidikan dan pengasuhan, dan perlindungan, untuk mengoptimalkan semua aspek perkembangan anak yang dilakukan secara terpadu oleh berbagai pemangku kepentingan di tingkat masyarakat, pemerintah daerah, dan pusat. Setiap PAUD diwajibkan untuk menjadi PAUD H-I, termasuk KB/TK Binarrahman. Memasuki tahun akademik ke 12, dengan beberapa perkembangan yang telah dicapai, Binarrahman memiliki beberapa masalah untuk mencapai hal tersebut yang harus segera diberikan solusi untuk mencapai PAUD Holistik. Dari beberapa permasalahan yang dihadapi oleh Binarahman di atas, beberapa masalah perlu segera diatasi yaitu pemantauan status gizi dan penanaman pendidikan kesehatan reproduksi dini untuk balita. Tujuan dari kegiatan pengabdian ini adalah untuk membantu mitra mencapai standar PAUD H-I dari segi kesehatan dan gizi. Solusi yang ditawarkan adalah pendampingan pemahaman gizi untuk balita dan pendampingan penanaman kesehatan reproduksi dini untuk balita. Pelaksanaan kegiatan pengabdian ini dibagi menjadi 3 tahap, yaitu persiapan, pelaksanaan, dan monitoring evaluasi. Hasil akhir diperoleh peningkatan pengetahuan guru-guru PAUD yang secara significan secara statistik.
\end{abstract}

Kata kunci: PAUD, Balita, hoslistik, gizi, kesehatan reproduksi

\begin{abstract}
The government has determined that PAUDs established must meet Holistic PAUD, in accordance with Presidential Regulation (PERPRES) No. 60 of 2013 concerning Holistic PAUD. Integrative Holistic Early Childhood Education is a comprehensive handling of early childhood which includes nutrition and health services, education and care, and protection, to optimize all aspects of child development carried out in an integrated manner by various stakeholders at the community, local government and central levels . Every PAUD is required to become a H-I PAUD, including KB / TK Binarrahman. Entering the 12th academic year, with several developments that have been achieved, Binarrahman has several problems to achieve this that must be immediately given a solution to achieve Holistic PAUD. Of the several problems faced by Binarahman above, several problems need to be addressed immediately, namely monitoring nutritional status and planting early reproductive health education for toddlers. The purpose of this community service activity is to help partners achieve H-I PAUD standards in terms of health and nutrition. The solutions offered are assistance in understanding nutrition for toddlers and assisting in planting early reproductive health for toddlers. The implementation of these service activities is divided into 3 stages, namely preparation, implementation, and evaluation monitoring. The final result is obtained statistically significant increase in the knowledge of PAUD teachers
\end{abstract}

Keywords: PAUD, children under five years, holistic, reproductive health 


\section{PENDAHULUAN}

Pemerintah telah menetapkan bahwa PAUD yang didirikan harus memenuhi PAUD Holistik, sesuai dengan Peraturan Presiden (PERPRES) No 60 Tahun 2013 tentang PAUD Holistik. PAUD Holistik Integratif adalah penanganan anak usia dini secara utuh (menyeluruh) yang mencakup layanan gizi dan kesehatan, pendidikan dan pengasuhan, dan perlindungan, untuk mengoptimalkan semua aspek perkembangan anak yang dilakukan secara terpadu oleh berbagai pemangku kepentingan di tingkat masyarakat, pemerintah daerah, dan pusat. Tujuan PAUD Holistik Integratif, secara umum adalah terselenggaranya layanan Pengembangan Anak Usia Dini Holistik-Integratif menuju terwujudnya anak Indonesia yang sehat, cerdas, ceria, dan berakhlak mulia, Sedangkan secara khusus adalah terpenuhinya kebutuhan esensial anak usia dini secara, terlindunginya anak dari segala bentuk kekerasan, penelantaran, perlakuan yang salah, dan eksploitasi di manapun anak berada, terselenggaranya pelayanan anak usia dini secara terintegrasi dan selaras antar lembaga layanan terkait, sesuai kondisi wilayah; dan terwujudnya komitmen seluruh unsur terkait yaitu orang tua, keluarga, masyarakat, Pemerintah dan Pemerintah Daerah. Pentingnya PAUD H-I adalah agar terwujud keterpaduan dari berbagai aspek yang akan membentuk anak usia dini yang utuh, yaitu aspek pendidikan, kesehatan dan gizi, pengasuhan, deteksi dini dan tumbuh kembang, serta aspek perlindungan.

Setiap PAUD diwajibkan untuk menjadi PAUD H-I, termasuk KB/TK Binarrahman. Memasuki tahun akademik ke 10, dengan beberapa perkembangan yang telah dicapai, Binarrahman memiliki beberapa masalah untuk mencapai hal tersebut yang harus segera diberikan solusi untuk mencapai PAUD Holistik.

Permasalahannya yang dihadapi yaitu belum terpenuhinya pemantauan status gizi secara rutin yang meliputi alat pemantauan status gizi berupa timbangan belum menggunakan timbangan digital, dan belum menggunakan microtoa, hasil pengukuran Tinggi Badan \& Berat Badan tidak di olah lebih lanjut sehingga belum diketahui hasil status gizinya, dan guru belum memahami teknis memberikan pendidikan kesehatan reproduksi pada anak dan orang tua karena masih dianggap tabu oleh masyarakat

Saat ini memang sudah dilakukan penimbangan dan pengukuran tinggi badan. Namun baru dilaksanakan sekali setiap satu semester dan alat antropometri yang dipakai hanya timbangan injak dan metilen sehingga validitas dan reliabilitasnya kurang terjamin. Selain itu, guru tidak melakukan analisis data dari hasil pengukuran sehingga tidak diketahui apakah siswa siswinya dalam kondisi status gizi sesuai umur dan jenis kelaminnya atau tidak.

\section{METODE PELAKSANAAN}

Pelaksanaan kegiatan pengabdian ini dibagi menjadi 3 tahap, yaitu persiapan, pelaksanaan, dan monitoring evaluasi.

1. Persiapan

a. Sosialisasi program kegiatan kepada guru yang bertujuan untuk memberikan penjelasan pentingnya kegiatan ini

b. Pre test diberikan kepada peserta untuk mengetahui pemahaman pada materi kegiatan ini

2. Pelaksanaan

a. Penyusunan bahan untuk kelas gizi dan pelatihan oleh nara sumber sesuai dengan tema yang sudah ditentukan

b. Kelas gizi pada balita

Pelaksanaan kegiatan ini dilaksanakan selama 2 kali pertemuan untuk memberikan materi gizi seimbang, antropometri, dan stunting, serta memotivasi realisasi gizi seimbang baik disekolah maupun di rumah. Kelas ini diisi oleh nara sumber dari latar belakang pendidikan gizi dan kesehatan masyarakat. 
c. Pelatihan antropometri gizi

Pelaksanaan kegiatan ini dilakukan dengan rincian :

1 : Pengukuran Berat badan dan tinggi badan

a. Nara sumber memberi contoh bagaimana melakukan penimbangan dengan digital scale dan pengukuran tinggi badan dengan microtoa kemudian secara bergantian, guru dan orang tua melakukannya

b. Setelah itu tak lupa hasilnya dicatat dalam buku atau telepon seluler masing-masing

c. Diskusi dan tanya jawab.

2: Analisis data

a. Download dan instal anthropometric calculator ke HP masing-masing

b. Memasukan data berat badan, tinggi badan, tanggal lahir, dan jenis kelamin

c. Membaca hasilnya untuk mengetahui keadaan gizi siswa

d. Guru diminta menuliskan hasilnya sekali dalam sebulan pada laporan perkembangan mingguan anak

e. Diskusi dan tanya jawab

d. Pelatihan kesehatan reproduksi dini

Pelatihan gizi seimbang dilakukan 1 pertemuan dengan rincian kegiatan :

1) Ciri fisik, sosial, kognitif anak usia dini

2) Pendidikan kesehatan reproduksi usia dini yang melibatkan seluruh anggota tubuh

3) Menanamkan pentingnya kesehatan reproduksi usia dini

4) Post test dari seluruh kegiatan yang dilaksanakan

3. Monitoring dan Evaluasi

Monitoring dan evaluasi dilaksanakan oleh tim pelaksana dan mahasiswa. Kegiatan ini dibagai menjadi 2 yaitu :

a. Monitoring dan Evaluasi nilai pre post test

Kegiatan yang dilakukan dikatakan berhasil apabila $80 \%$ peserta mengalami peningkatan nilai

b. Monitoring dan evaluasi implemetasi

\section{HASIL DAN PEMBAHASAN}

Berdasarkan identifikasi awal permasalahan yang sudah disampaikan diatas, solusi yang dilaksanakan dibagi menjadi 3 tahap dengan hasil sebagai berikut :

1. Sosialisasi kegiatan

Dilakukan oleh tim Pengabdian kepada guru-guru sekolah Binarrahman tentang tujuan kegiatan, konsep kegiatan, hasil yang diharapkan dan monitoring evaluasi kegiatan.

2. Pelatihan kesehatan

a. Kelas gizi

Materi yang disampaikan meliputi antropometri gizi :

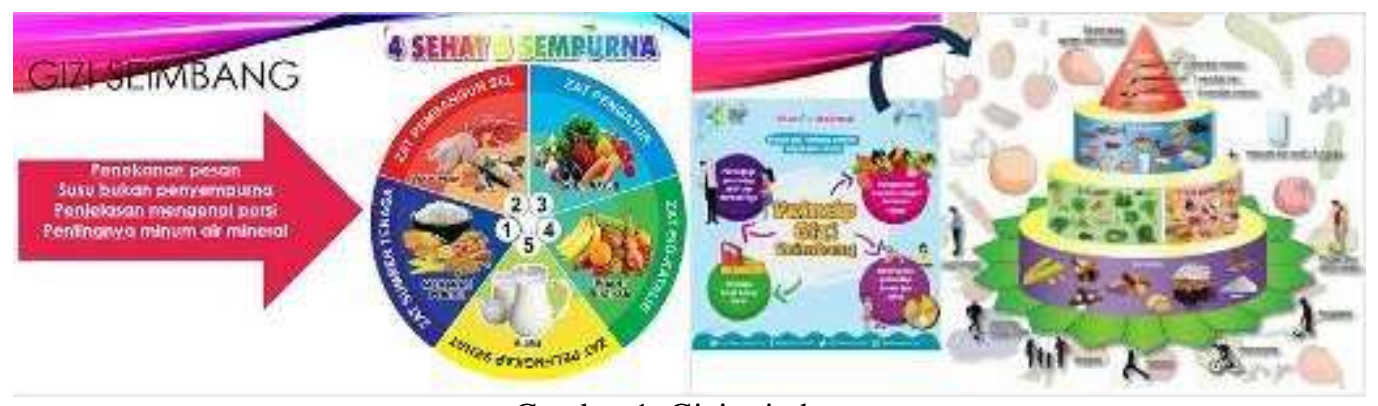

Gambar 1. Gizi seimbang

Pada awal memberikan materi ini, tim mencoba melaksanakan pre test diawal tentang konsep gizi seimbang. Hampir semua menjawab 4 sehat lima sempurna, padahal konsep tersebut sudah lama berganti. Dalam upaya mengoptimalkan penyampaian pesan Gizi Seimbang kepada masyarakat, diperlukan komunikasi, informasi dan edukasi yangtepat 
dan berbasis masyarakat. Pendidikan dan penyuluhan gizi denga nmenggunakan slogan 4 Sehat 5 Sempurna yang dimulai 1952, telah berhasil menanamkan pengertian tentang pentingnya gizi dan kemudian merubah perilaku konsumsi masyarakat. Prinsip 4 Sehat 5 Sempurna yang diperkenalkan oleh Bapak Gizi Indonesia Prof. Poorwo Soedarmo yang terinspirasi dari Basic Four Amerika Serikat yang mulaidiperkenalkan pada era 1940an adalah menu makanan yang terdiri darimakanan pokok, lauk pauk, sayuran dan buah-buahan, serta minum susu untuk menyempurnakan menu tersebut. Namun slogan tersebut sudah tidak sesuai lagi dengan perkembangan ilmu dan permasalahan gizi dewasa ini sehingga perlu diperbarui dengan slogan dan visual yangsesuai dengan kondisi saat ini. Sehingga berdasarkan Peraturan Menteri Kesehatan RI No.41 tahun 2014, konsep gizi seimbang terdiri dari 4 pilar mencakup konsumsi makanan beragam, membiasakan perilaku hidup bersih, melakukan aktivitas fisik, mempertahankan dan memantau berat badan dalam kisaran normal. [1]

Selain materi gizi seimbang, disampaikan juga materi antropometri gizi dan praktek sebagai berikut :
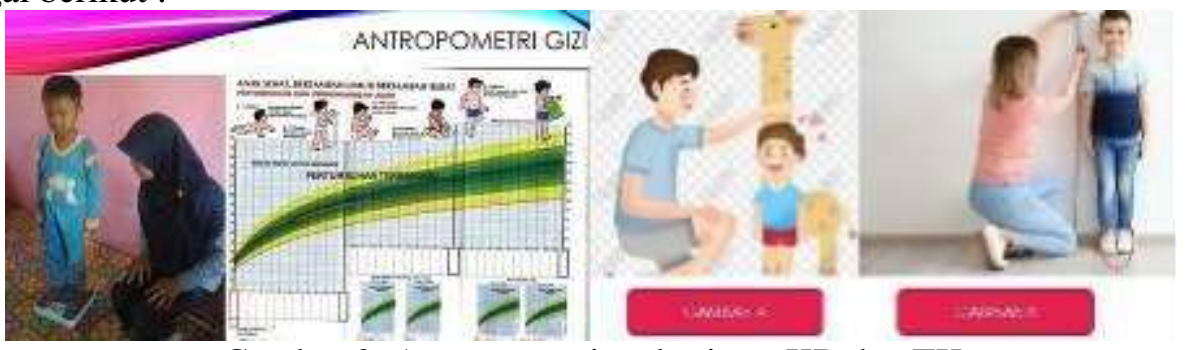

Gambar 2. Antropometri pada siswa KB dan TK

Praktek antropometri yang dilakukan adalah penimbangan dengan menggunakan digital scale dan pengukuran tinggi badan menggunakan microtoa. Penekanan pengukuran ini dilakukan untuk menekankan bahwa pemakaian baju yang seminimal mungkin dan sepatu dilepas agar hasil pengukuran tidak bias.

Hasil pengukuran selama ini hanya dicatat berat badan dan tinggi badan saja tanpa dilakukan analisis status gizi anak berdasarkan antropometri. Pada kesempatan ini, tim memberikan materi cara menganalisis hasil pengukuran dengan software anthropometric calculator sebagai berikut :

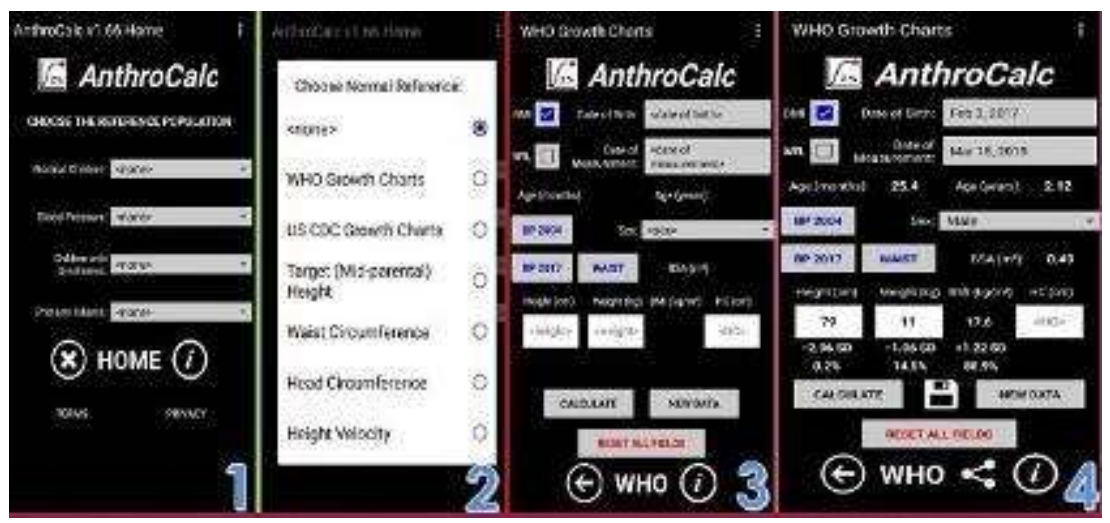

Gambar 3. Langkah-langkah menghitung status gizi dengan indeks BB/U dan TB/U

b. Kelas reproduksi anak usia dini

Materi yang disampaikan sebagai berikut : 

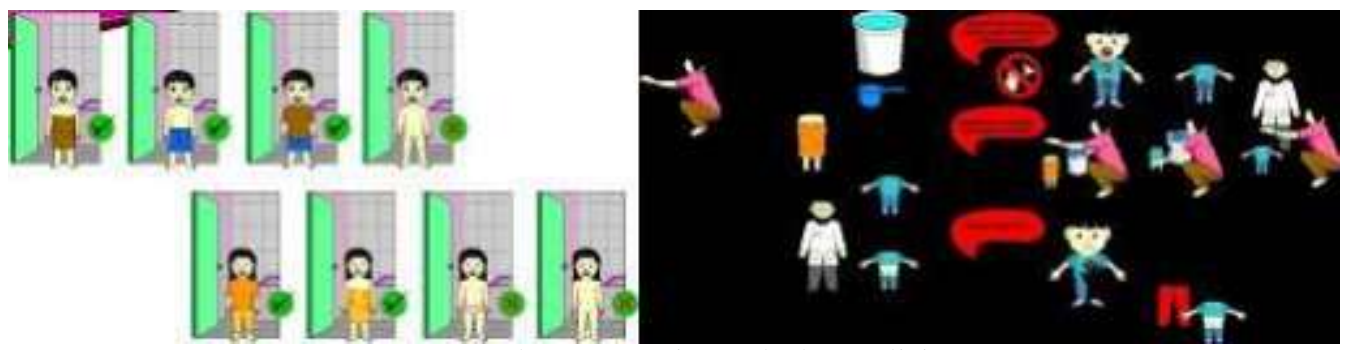

Gambar 4. Bagian tubuh sendiri

Pada awal penyampaian materi, beberapa peserta beranggapan materi reproduksi terkait dengan kehamilan dan lain-lainnya. Mereka belum menerima materi seperti tersebut. Sehingga hal ini dirasakan sangat bermanfaat untuk disampaikan ke siswanya. Banyaknya permasalahan kesehatan reproduksi yang timbul sejak masa janin hingga remaja seperti kekurangan gizi kronis, rendahnya pemberian ASI eksklusif, pernikahan usia anak, kehamilan yang tidak diinginkan menyebabkan kesehatan reproduksi sejak masa anak penting untuk diperhatikan oleh berbagai pihak, termasuk pemangku kebijakan. Dalam hal ini kesehatan reproduksi yang dijaga sedini mungkin akan berperan penting dalam mengurangi angka kematian ibu dan bayi.[2]

Berikut adalah dokumentasi kegiatan saat dilaksanakan kelas materi.

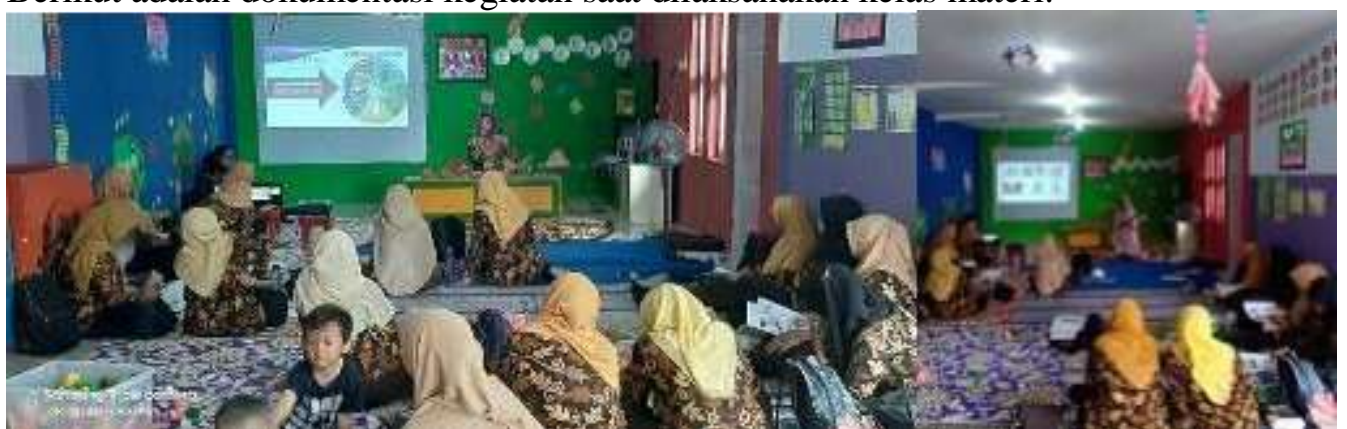

Gambar 5. Dokumentasi kegiatan pengabdian

3. Monitoring dan Evaluasi Kegiatan

Pelaksanaan sebuah kegiatan dikatakan berhasil jika sudah mencapai indikator yang ditetapkan. Begitu pula dengan kegiatan ini, peserta menjawab soal pre test dan post test yang secara statistic menunjukkan adanya perbedaan dengan tingkat kesalahan $10 \%$. Rerata nilai pre test 12,06 dan nilai post test 12,94 . Ada kenaikan nilai setelah pemberian materi kelas gizi dan reproduksi anak usia dini $(\mathrm{p}<0,05)$.

\section{KESIMPULAN DAN SARAN}

Metode pelatihan kesehatan anak usia dini dengan konsep kelas gizi dan kesehatan reproduksi dini secara statistik efektif untuk meningkatkan pengetahuan guru $(\mathrm{p}<0,05)$. Berdasarkan hasil tersebut, direkomendasikan untuk terus melakukan kegiatan serupa dengan topik-topik lain yang dapat mendukung terwujudnya PAUD-HI.

\section{DAFTAR PUSTAKA}

[1] M. Kesehatan, "Peraturan Menteri Kesehatan No. 41 tahun 2014," in Peraturan Menteri Kesehatan No. 41 tahun 2014 tentang Pedoman gizi seimbang, 2014.

[2] I. A. Tedju Hinga, "PENCEGAHAN KEKERASAN SEKSUAL PADA ANAK MELALUI EDUKASI KESEHATAN REPRODUKSI BERBASIS MEDIA PADA MURID SEKOLAH PENDIDIKAN ANAK USIA DINI (PAUD)," GEMASSIKA $J$. Pengabdi. Kpd. Masy., 2019. 